\title{
Customer Engagement with Universities' Social Media after COVID-19: EaP Countries Case
}

\author{
Nina Chala ${ }^{1}$, Kateryna Pichyk $^{1}$, Olga Voropai $^{1}$, and Olena Bilovodska ${ }^{2 *}$ \\ ${ }^{1}$ National University of Kyiv Mohyla Academy, Marketing and Business Management Department, \\ 04070, 2 Skovorody Street, Kyiv, Ukraine \\ ${ }^{2}$ Taras Shevchenko National University of Kyiv, Department of International Economics and \\ Marketing, 01033, 60, Volodymyrska Street, Kyiv, Ukraine
}

\begin{abstract}
The current research aims at analyzing the social media activity of the universities in EaP countries. During the COVID-19 pandemic, universities had to transfer their education processes and enrollment campaigns online. University management had to introduce new tools for communication and interaction to ensure the efficacy of cooperation between the university community, students, teaching staff, and other stakeholders. In this research, the authors analyze which factors affected the dynamics and directions of customer engagement with Universities' social media and how. The authors propose a framework to reveal the role of countries' digital environment, educational environment, and university's SM activity in increasing ER of university stakeholders during the COVID-19 pandemic on Facebook and Instagram. The authors outline managerial proposals for universities, including analytics-based SM content creation and planning, communicating socially essential issues. Keywords: universities' social media, COVID-19, Facebook, Instagram.
\end{abstract}

\section{Introduction}

Higher education institutions (HEI) widely use SM to communicate with their clients, increase brand loyalty, co-create value with students, academic staff, and other stakeholders. However, depending on the university's goals and objectives, the marketing role of SM use differs and is often underestimated.

Several studies investigate how universities use SM for public relations and university brand-building and include a qualitative, sentimental, and quantitative content analysis of the posts and corresponding users' Engagement rate (ER). HEI researchers and managers are interested in the role of customer engagement with Facebook and other SM pages towards prospective student enrolment. Several studies are devoted to SM usage by separate university departments. Ihejirika K., Goulding A., Calvert Ph. suggest applying a strategic approach to implementing SM into the academic libraries' marketing practice [1]. Roopchund R., Ramesh V., Jaunky V. C. indicate the effectiveness of introducing SM into the education process by faculty staff to enhance a higher level of students' communication and engagement [2]. All these activities become a part of a more strategic value co-creation

\footnotetext{
* Corresponding author: o.bilovodska@gmail.com
} 
process. Value co-creation plays an essential role in attracting active participants to the university community. It helps to develop innovations and develop new services and products. The paper by Al-Kumain N. H., Alhazmi A., Rmayah T., Shabbir M. S., Gazem $\mathrm{N}$. explores the use of online platforms for value creation by Malaysian universities, including crowdfunding platforms for attracting funding for innovative development [3]. Within the framework of the current research, we consider the processes by which universities create value for their clients on social networks, which were covered in the papers by Voropai O., Pichyk K., Chala N. [4] and Horodovenko V., Bilovodska O., Vatras V., Kanzafarova I., Melnyk R. [5]. However, we shift the focus of this paper to the COVID-19 period, which has forced universities to become more active in SM.

The impact of the COVID-19 pandemic on universities and their interaction with students is only in the spotlight of researchers. This can be exploited by the mass transition of universities to distance learning, which took place a year ago. This transition is largescale and unprecedented as it has never been before. In addition, we are currently unable to envisage and report all the consequences of such a situation. For example, a study conducted by the Office for National Statistics found that students were more responsive to quarantine restrictions than ordinary citizens [6]. More than $29 \%$ of students surveyed reported a negative experience of distance learning, and more than 53\% of students reported a deterioration in well-being and mental health due to distance learning. The numbers highlight the need for universities to interact with students.

Research on the impact of COVID-19 on universities focuses mainly on the effectiveness of distance learning and future models of blended and hybrid learning [7, 8]. Fenwick M., McCahery J. A., Vermeulen E. concentrate on accelerating the digital transformation and IT support of higher education [9]. Gezmen B., Eken I. analyze individual adaptation to online learning, time costs, workload, and the overall level of student satisfaction with new learning forms and tools [10].

Scarce research studies on HEI social media usage in post-COVID times consider communication in social networks in the context of the efficiency of the educational process and knowledge delivery via TikTok [11] and YouTube [12, 13]. The interaction between universities and their community, stakeholders, enrollees in the conditions of strict lockdown has not been studied. Therefore, the presented work is unique.

\section{Materials and methods}

We use our research to investigate how the COVID-19 pandemic influenced the established order of things in the interaction between universities and their stakeholders through social media. Fig. 1 depicts our conceptual framework, which views customer engagement as an outcome of such interaction. The COVID-19 pandemic and the corresponding local and global policy changes that equally severely affected all the countries in the region highly disrupted the whole process and its results. Nevertheless, we suppose that the level of reaction and changes differs in different countries. We consider the main factor that may have influenced such differences is institutions' activity in social media.

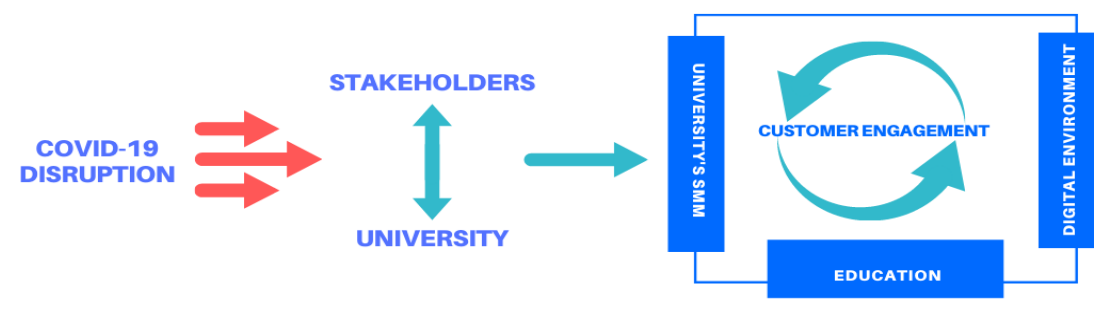

Fig. 1. Conceptual framework 
In this study, we addressed the main research question:

Are social media activities of the universities in post-pandemic in line with what their stakeholders expect and are willing to engage with?

We selected the five most influential universities in each Eastern Partnership country based on the academic impact study*. An academic impact rating InfluenceRanking is created based on data analysis from open sources in different languages regarding citations, references, achievements of the university community [14]. Thus, this rating considers scientific achievements, publishing activity of university representatives, and recollections in mass media, social networks, etc. Machine learning algorithms are used for data analysis, which makes it possible to update the data quarterly.

The research included Facebook and Instagram as the most popular social media platforms in EaP countries, according to Datareportal [15].

We investigated two periods - March-September 2019 (pre-COVID-19) and MarchSeptember 2020 (COVID-19) - to compare the interaction of universities through social networks before and during the coronavirus pandemic. We considered only the official pages of universities on social networks. We excluded information and interaction with the audience of individual pages of teachers, administration, departments that do not have "links" to the official from our analysis.

We collected an array of data from the official pages of universities on social networks: the number of subscribers, posts, likes, shares, and comments*. We also extracted data on the level of SM engagement using Popsters software [16].

To track down the level of user engagement after COVID-19 in social networks, in this section, we will use the following metrics for Facebook and Instagram [16]:

- Number of fans

- Fans/students ratio

- Engagement rate per post

- Engagement rate per day

- Number of comments

- Number of likes

- Love rate

- Talk rate

Additional metrics were introduced to cluster universities and to check hypotheses on a country level:

- University posting rank. Each university is assigned points depending on its SM activity dynamics in Facebook and Instagram.

0 points - no activity.

-1 point - the page terminated.

1 point - negative posting dynamics.

2 points - positive posting dynamics.

- Country posting rank is a sum of average posting ranks for all five universities in a given country.

- University ER rank. Each university is assigned points depending on its users' activity dynamics on Facebook and Instagram.

0 - know university SM page or page terminated.

1 - negative ER dynamics.

2 - positive ER dynamics.

- Country ER rank is a sum of average ER ranks for all five universities in a given country.

\footnotetext{
${ }^{*}$ The full list of official social media pages of the universities from this research can be seen at https://drive.google.com/file/d/1xBZGgQPuH2JN2 M7R-mPLMWC-ftQzPxg/view? usp=sharing
} 


\section{Results and discussions}

\subsection{Universities' SMM}

The last group of moderating factors we examined is the universities' social media marketing policies. Therefore, we intended to check whether universities in the EaP countries integrate a proactive and analytics-based SMM as a part of their communication strategy in COVID-19 pandemic times.

H1: Universities fall behind in their SM activity: the dynamics of the firm-generated content (FGC) (number of posts) is lower than the dynamics of the customer engagement (ER).

To test this hypothesis for each university, we determine the average level of activity on both social networks (University posting rank). Accordingly, we also rank the activity of users (University ER rank). We show the results in Fig. 2. for each university and Fig. 3 for each EaP country.

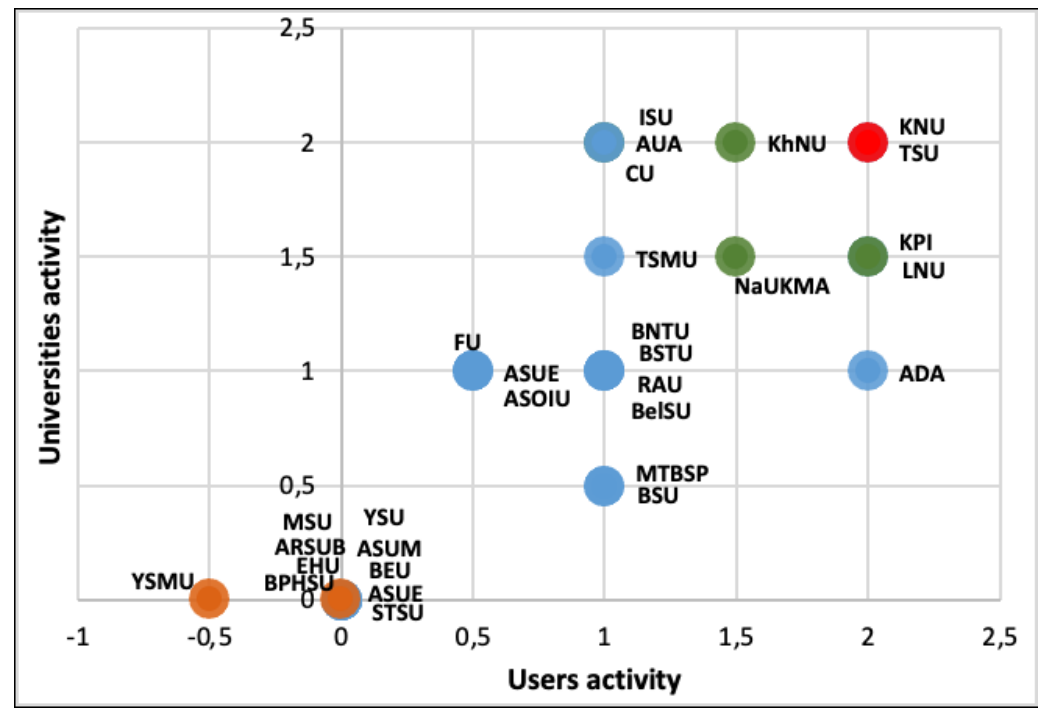

Fig. 2. The average level of activity for each university.

Thus, as can be seen from the matrix, only two universities have the best SM activity indicators $(2 ; 2)$ : TSU and KNU. They are constantly active, and their users are just as responsive. We call them the "VIP" segment.

The next group of universities belongs to the "Growing" segment. NaUKMA, LNU, KPI, KhNU - are educational institutions that demonstrate activity growth in at least one social network. Users, respectively, also responded adequately and increased interest in the proposed content.

The largest segment of "Newbies" includes $47 \%$ of the universities in question: RAU, ASUE, ISU, AUA, CU, TSMU, ADA, BSU, ASOIU, BelSU, MTBSP, BSTU, BNTU, FU. These educational institutions have not increased their activity in social networks, or vice versa - their users have not increased their interest in the proposed content. 
The worst situation is with the "Lost" segment - universities that do not have social network pages or closed their pages in the studied period. Unfortunately, 33\% of the universities turned out to be in this segment.

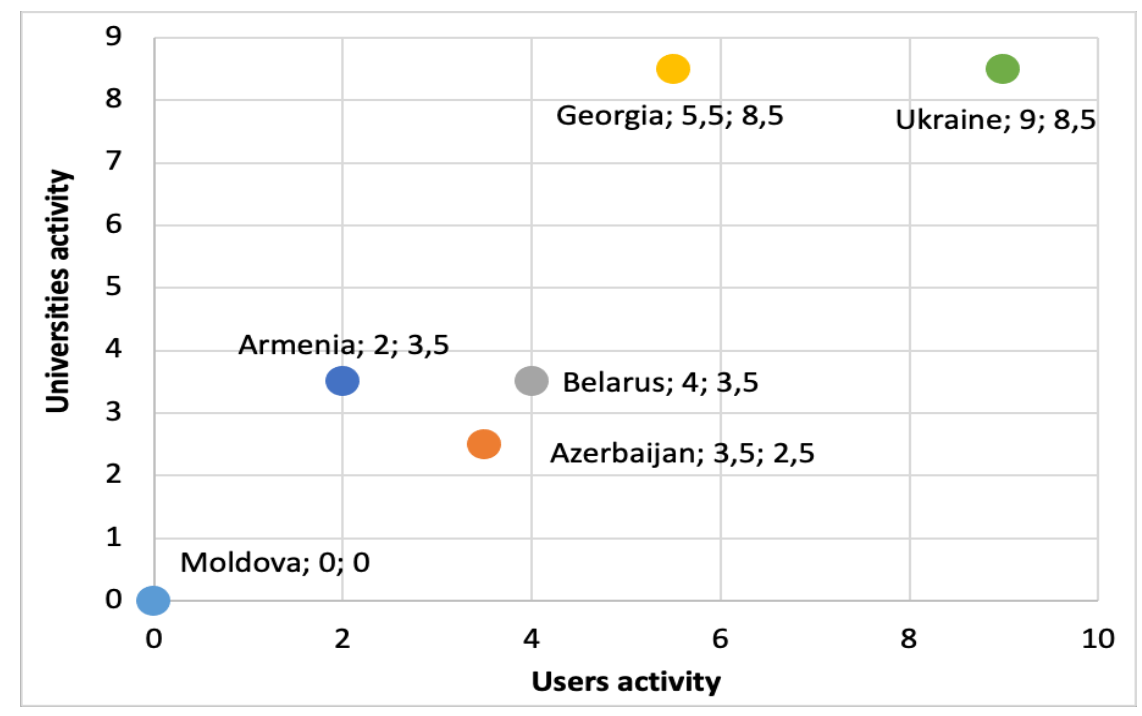

Fig. 3. The average level of activity for each EaP country.

As we can see, the universities of most countries (Fig. 3) did not set themselves the task of increasing the interaction with their stakeholders. However, in some educational institutions, the activity of the users themselves has increased. Thus, we can say that users want to receive news and other content from the university and are willing to actively respond by increasing the number of likes, comments, etc.

H2: Universities increase the content type according to the ER and stakeholders' preferences.

The next logical question is whether universities base their SM content decisions on users' reactions and engagement data. To test hypothesis $\mathrm{H} 2$, we selected seven universities that have increased activity in social networks from 2019 to 2020. These are TSU, KNU, LNU, NaUKMA, KPI, KhNU, ADA. First, we defined what type of content received the most significant response among users in 2019. We then checked whether educational institutions increased their activity relative using the most popular type of content in the COVID-19 period.

As can be seen, for Instagram, the results are pretty obvious (Fig. 4): Text and Photos have the highest ER. Moreover, in 2020, the universities we considered increased the production of this type of content. The Ukrainian institution KPI demonstrated extraordinary growth. It increased the usage of these content types 66 and 31 times, respectively. As can be seen, the leader in content growth in 2020 is video.

Nevertheless, not all institutions get an enthusiastic reaction to it from stakeholders. The results of the study for Facebook (Fig. 5) are not so noticeable. Each educational institution had a different dominating type of content. However, the most significant increase is seen in video posts. Moreover, although users have actively responded to all content types, some educational institutions reduced the number of posts of a specific type. 


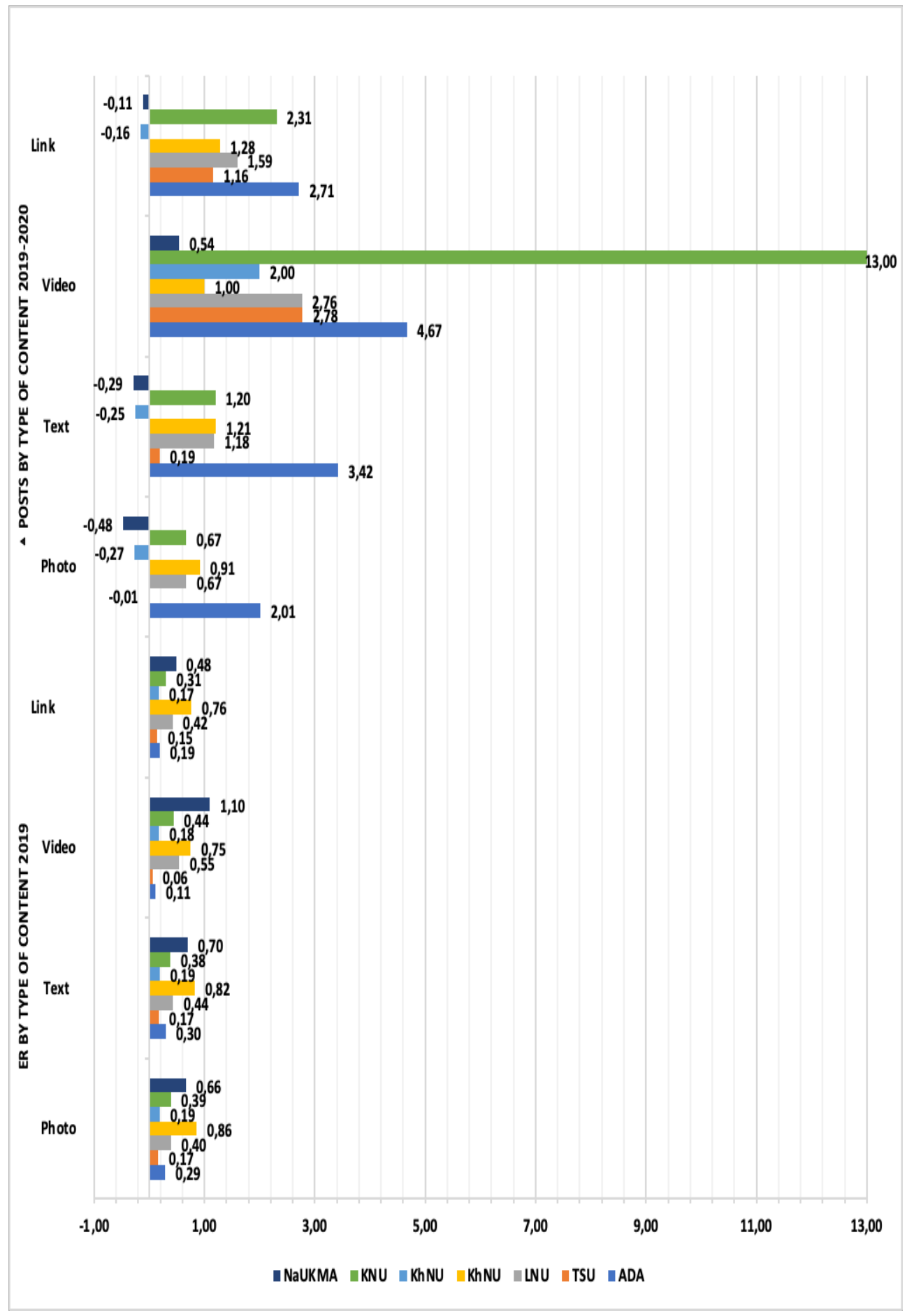

Fig. 4. Using analytics to manage content on Instagram. 


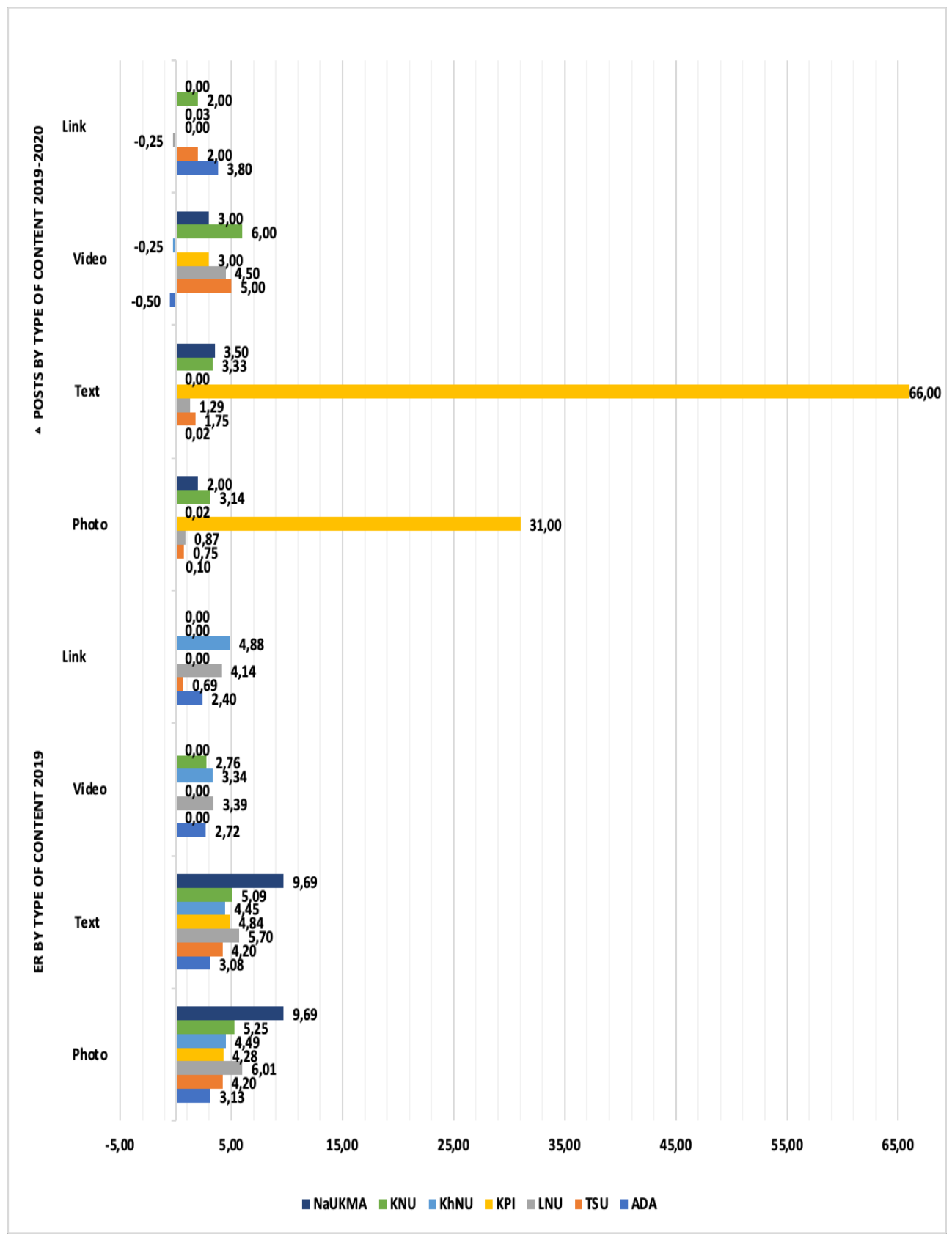

Fig. 5. Using analytics to manage content on Facebook.

\subsection{Research implications}

In this section, we outline opportunities for further research. A similar study needs to be done for an extended time frame, including 2021 and 2022 (when we talk about life after the COVID-19 pandemic and the new normal). The research can be based on the framework we presented. However, taking into account the results, researchers may 
eliminate some of the hypotheses. Below is the list of possible remaining assumptions for post-COVID-19 research:

- H1: Universities fall behind in their SM activity: the dynamics of the FGC (number of posts) is lower than the dynamics of the customer engagement (ER).

- H2: Universities increase the content type according to the ER and stakeholders' preferences.

Despite the pandemic slowing down, countries continue using restrictions that affect higher education. Therefore, it is necessary to follow which of the changes in the CM will remain and which will not have inertial development. Will the social activity of universities intensify in the post-COVID-19 period as a response to users' engagement? Will users demonstrate the same level of involvement? Or will both groups show high levels of "digital fatigue"?

Furthermore, a conceptual framework is needed to define certain places of different types of SM in the University managerial processes. Based on the best global practices, such framework will show educational institutions from EaP countries how to benefit from SM not only for communication purposes but also for improving value proposition (e.g., distance student mobility, professional mentoring and expertise), employment (e.g., LinkedIn or other professional networks), enrollee attraction (e.g., TikTok or new emerging SM for youth). This approach should concentrate not on the specific SM (as their popularity and penetration are different in different regions) but their function and target audiences.

Consequently, such a framework will imply an analytics-based approach to content creation. Future research papers must analyze the content and topics that elicit user responses. How crucial is the role of UGC (user-generated content) and FGC (firmgenerated content) in the market of educational services? How to determine the optimal structure of UG and FG content. At what stage of the student's life cycle does the active participation with universities' SM terminate? Moreover, is it possible to extend the student's lifetime within the university scope using SM tools?

\subsection{Managerial implications for universities}

The process of managing profiles on social networks remains challenging to understand for university management. Our research shows that almost no university builds its communication on social networks based on analytical data. Analyzing the information offered by universities, we found that different types of content may predominate for various social networks, and, accordingly, users may prefer other activities from educational institutions. The choice of the content type is random rather than reasonable.

Currently, universities operate haphazardly without analyzing statistics on the preferences of their stakeholders. Such actions can negatively affect user interest and reduce the number of followers. By collecting and analyzing statistics on information preferences and responding accordingly, universities will increase the number of interested users and actively attract new ones by disseminating information about themselves in the world.

The same random approach is used when choosing the social networks themselves. Users have become more active across various social networks. Still, the universities of the Eastern Partnership countries are in the paradigm of "sales" thinking, when the main university product is the curriculum, and the primary target audience is the enrollee. The universities of the Eastern Partnership countries do not pay enough attention to the development of interaction with stakeholders in the digital space and social networks, as shown by the presented analysis. The scarce activity of universities in professional networks (Linkedin and others) indicates traditional employment assistance methods. The pull of the most used SM suggests a lack of understanding and segmentation of the target 
audience. Universities prefer Facebook, while recent statistics reveal, for instance, that Ukrainian students prefer Telegram and Instagram [17].

It is also worth noting that informal profiles of university communities, pages of individual departments, and divisions were left out of our attention. Nevertheless, such profiles exist. Moreover, they are a part of the process of building effective communication on social networks. Therefore, universities must decide on the level of decentralization of this process. On the one hand, decentralization will make content relevant to different target groups and provide higher ER.

However, as they increase their activity, universities must be prepared for positive and negative feedback, affecting the HEI's reputation $[5,18,19]$. Though some authors outline the possible negative market value effect from customer engagement initiatives for public companies, they clarify that less advertised companies (e.i. Universities) can benefit from it [20]. Accordingly, this confirms that universities should be active in social networks and collect and analyze statistics of their activities. Examine the comments, both positive and negative, because their consideration can increase the competitiveness of educational institutions not only in the local but also in the global market of educational services.

\section{Conclusions}

This paper focuses on how the online engagement of university stakeholders changed during the COVID-19 pandemic to meet their communication needs in the new reality. Our framework focuses on three factors modifying the COVID-19 influence on ER in six countries of the Eastern Partnership. The main factor that may have influenced such differences is the SMM policies of the Universities. We propose several further research directions, including the post-COVID-19 monitoring analyses and deeper content examination. As the research results reveal a favorable external environment for further customer engagement but a highly underestimated SM role inside the University management teams, we outline the number of managerial implications for universities.

\section{References}

1. K. Ihejirika, A. Goulding, Ph. Calvert, J. Libr. Adm., 61 (1), 58-85 (2021).

2. R. Roopchund, V. Ramesh, V. C. Jaunky, Use of Social Media for Improving Student Engagement at Université Des Mascareignes (UDM), in Information Systems Design and Intelligent Applications. Proceedings of Fifth International Conference INDIA, Vol. 2 / [ed] S.C. Satapathy, V. Bhateja, R. Somanah, X.Sh. Yang, R. Senkerik (2018).

3. N. H. Al-Kumain, A. Alhazmi, T. Rmayah, M. S. Shabbir, N. Gazem (2021), Sustaining Continuous Engagement in Value Co-creation Among Individuals in Universities Using Online Platforms: Role of Knowledge Self-efficacy, Commitment and Perceived Benefits, Front. Psychol. (published electronically February 12), (2021).

4. O. Voropai, K. Pichyk, N. Chala, Economics and Sociology, 12 (4), 214-226 (2019).

5. V. Horodovenko, O. Bilovodska, V. Vatras, I. Kanzafarova, R. Melnyk, Estudios de Economia Aplicada, 9 (7), Sp. Is.: Impact of Current Trends in Social Commerce, Economics, and Business Analytics (2021).

6. Office for National Statistics, Coronavirus and the Impact on Students in Higher Education in England: September to December 2020, London: ONS (2020).

7. V. Govindarajan, A. Srivastava, Harvard Bus. Rev. (March), (2020).

8. S. N. Mohd Anis, M. A. Ibrahim, L. Mohd Tahir, B. Abu, A. Khan, and R. A. Azizi, J. Adv. Res. Dyn. Contr. Syst., 12 (7) (Special issue), 2929-2933 (2020). 
9. M. Fenwick, J. A. McCahery, E. P.M. Vermeulen, EBOR, 22 (1), 125-145 (2021).

10. B. Gesmen, I. Eken, Students' Satisfaction with Applications Implemented in Distance Education Process During the Pandemic Period, in Management Strategies to Survive in a Competitive Environment. Contributions to Management Science, H. Dincer, S. Yüksel, eds., Cham: Springer International Publishing, 75-89 (2021).

11. P. Escamilla-Fajardo, M. Alguacil, S. López-Carril, J. Hosp. Leis. Sport TO, 28 (2021)

12. Y. Zulnaidi, N. H. Md Saad, TEM Journal, 9 (4), 1732-1739 (2020).

13. D. Tolkach, S. Pratt, J. Hosp. Leis. Sport TO, 28 (published electronically March 14), (2021).

14. The InfluenceRanking ${ }^{\mathrm{TM}}$ Engine: Our Ranking Technology Explained, Academic Influence, (accessed April 2021), (2021).

15. Complete Report Library, Datareportal, accessed June 14, 2021, https://datareportal.com/library (2021).

16. Engagement Rate: How to Calculate ER for Social Media Properly, Popsters, https://popsters.com/blog/post/er-how-to-calculate-engagement-rate (2017).

17. Attitude of the Population to the Media and Consumption of Different Types of Media in 2020, Research Report InMind August (2020).

18. S. Kvitka, G. Starushenko, V. Koval, H. Deforzh, O. Prokopenko, Marketing of Ukrainian higher educational institutions representation based on modeling of webometrics ranking. Marketing and Management of Innovations, 3, 60-72 (2019).

19. O.V. Prokopenko, A.M. Karminsky, O.V. Klymenko, The role of ratings in the educational process of higher education institutions. Marketing and Management of Innovations, 4(2), 141-146 (2011).

20. F.M. Beckers Sander, J. van Doorn, P.C. Verhoef, Good, Better, Engaged? The Effect of Company-Initiated Customer Engagement Behavior on Shareholder Value, J. Acad. Market. Sci., 46, 366-383 (2018). 